\title{
A Building Block Approach to Photochemical Water-Splitting Catalysts Based on Layered Niobate Nanosheets
}

\author{
Owen C. Compton, ${ }^{\dagger}$ Cory H. Mullet, $₫$ Shirley Chiang, $₫$ and Frank E. Osterloh $*$, \\ Department of Chemistry, Department of Physics, University of California, Davis, \\ One Shields Avenue, Davis, California 95616
}

Received: December 9, 2007; In Final Form: February 5, 2008

\begin{abstract}
We present a modular approach to the synthesis of nanostructured catalysts for photochemical splitting of water into hydrogen and oxygen. The catalysts are built from exfoliated, semiconducting niobate nanosheets derived from the layered perovskite $\mathrm{HCa}_{2} \mathrm{Nb}_{3} \mathrm{O}_{10}$. The latter is a catalyst for photochemical evolution of hydrogen from water under UV irradiation. After chemical modification with 3-aminopropyltrimethoxysilane (APS), $\mathrm{IrO}_{2}$ or Pt particles can be attached to the nanosheets to produce various two-component nanostructures that were fully characterized with transmission electron microscopy and ultraviolet and infrared spectroscopy. Cyclic voltammetry was used to determine the onset potentials for $\mathrm{O}_{2}$ and $\mathrm{H}_{2}$ evolution. At $\mathrm{pH}=14$, the observed values are in the range +0.61 to $+1.24 \mathrm{~V}$ (NHE, water oxidation) and -1.36 to $-1.62 \mathrm{~V}$ (NHE, water reduction). Under UV irradiation, all catalysts evolve hydrogen from water without any sign of deactivation for $5 \mathrm{~h}$. The highest quantum efficiency of $3.49 \%$ is observed for a structure with Pt directly grown onto the nanosheets. $\mathrm{No}_{2}$ is evolved, which we attribute to the adsorption of $\mathrm{O}_{2}$ to the catalyst surface. For Pt- $\left[\mathrm{HCa}_{2} \mathrm{Nb}_{3} \mathrm{O}_{10}\right]$, this process starts to shut down $\mathrm{H}_{2}$ evolution after $9 \mathrm{~h}$ of constant irradiation, but the activity can be restored to $>60 \%$ by evacuating the catalyst dispersion and purging it with Ar. Catalysts assembled from preformed citrate-coated Pt nanoparticles are slightly less active for $\mathrm{H}_{2}$ evolution and so are catalysts that use the linker aminoethyl-aminoundecanetrimethoxysilane (AEAUS) instead of APS. The activity of $\mathrm{IrO}_{2}$-APS- $\left[\mathrm{Ca}_{2} \mathrm{Nb}_{3} \mathrm{O}_{10}\right]$ is lowest among two component catalysts, near the activities of the pure or APSmodified nanosheets. On the basis of XPS data, $\mathrm{IrO}_{2}$ in this catalyst undergoes photochemical reduction to $\operatorname{Ir}(0)$ upon UV irradiation.
\end{abstract}

\section{Introduction}

The efficient conversion of solar energy into chemical fuels has great economic and environmental significance. ${ }^{1}$ In 1971, Fujishima and Honda reported that a $\mathrm{TiO}_{2}$ (rutile) photoanode photochemically split water into $\mathrm{H}_{2}$ and $\mathrm{O}_{2}$ under irradiation with UV light and under a small applied electrochemical potential. ${ }^{2,3}$ Since then, over 130 semiconductors have been identified as catalysts for photochemical splitting of water. ${ }^{4-9}$ Particular interest has been devoted to semiconductors based on layered niobates because of their ability to intercalate sensitizers and cocatalysts ${ }^{10-13}$ and because of their good quantum efficiencies $\left(20 \%\right.$ for $\left.\mathrm{K}_{4} \mathrm{Nb}_{6} \mathrm{O}_{17}\right) .{ }^{11}$ The Dion-Jacobsen phase $\mathrm{KCa}_{2} \mathrm{Nb}_{3} \mathrm{O}_{10}$ has been known mostly for its photocatalytic methanol dehydrogenation activity, but a recent report by Ebina showed that in combination with $\mathrm{RuO}_{2}$ particles, this semiconductor can also split water under UV irradiation. ${ }^{14} \mathrm{We}$ found that the ability to photocatalytically evolve $\mathrm{H}_{2}$ from water is retained in individual $\mathrm{TBA}\left[\mathrm{Ca}_{2} \mathrm{Nb}_{3} \mathrm{O}_{10}\right]$ nanosheets that are obtained by exfoliating the parent solid with tetrabutylammonium (TBA) hydroxide. ${ }^{15}$ These sheets are $\sim 1 \mathrm{~nm}$ thick and consist of triple stacks of edge-shared $\mathrm{NbO}_{6}$ with intercalated $\mathrm{Ca}^{2+}$ ions, as shown in Figure 1. On the basis of transient absorption spectroscopy, photogenerated charge carriers in the sheets recombine on a subnanosecond time scale following

* To whom correspondence should be addressed. E-mail: fosterloh@ ucdavis.edu. Fax: (+1) 530752 8995. Tel: (+1) 5307526242.

Department of Chemistry.

Department of Physics. second-order kinetics. ${ }^{16}$ In extension of our previous work on $\mathrm{Ca}_{2} \mathrm{Nb}_{3} \mathrm{O}_{10}-\mathrm{CdSe} / \mathrm{Au} /-\mathrm{Fe}_{3} \mathrm{O}_{4}$ nanoparticle composites, ${ }^{17-19}$ we demonstrate here that exfoliated $\left[\mathrm{HCa}_{2} \mathrm{Nb}_{3} \mathrm{O}_{10}\right]$ nanosheets can be integrated into two-component nanostructures $\left[\mathrm{Ca}_{2} \mathrm{Nb}_{3} \mathrm{O}_{10}\right]$ $\mathrm{L}-\mathrm{M},\left(\mathrm{M}=\mathrm{Pt}\right.$ or $\left.\mathrm{IrO}_{2}\right)$ that are supported by $\gamma$-aminoalkyltrimethoxysilanes as organic linkers. Platinum nanoparticles are commonly employed as a cocatalysts for water reduction, ${ }^{5}$ and $\mathrm{IrO}_{2}$ is one of the most active water oxidation catalysts. ${ }^{20,21} \mathrm{We}$ find that the photocatalytic properties of the dual component nanostructures are enhanced compared to the separate building blocks, and that the catalytic activity depends on the linker molecule and the method of assembly.

\section{Experimental Section}

Materials. Potassium hexachloroiridate (Strem, 99\% purity), anhydrous dimethylsulfoxide (DMSO, Acros Organics, 99.7\% purity), 3-aminopropyl trimethoxysilane (APS, Gelest), and $\mathrm{N}$-(2-aminoethyl) 11-aminoundecyl trimethoxysilane (AEAUS, Gelest) were used as received. $\mathrm{K}_{2} \mathrm{CO}_{3}\left(98.5 \%\right.$ purity), $\mathrm{CaCO}_{3}$ $(98.5 \%), \mathrm{Nb}_{2} \mathrm{O}_{5}(99.5 \%$ purity), tetrabutylammonium hydroxide (TBA $(\mathrm{OH})), 40$ wt \% solution in water), and hexachloroiridic acid $\left(\mathrm{H}_{2} \mathrm{IrCl}_{6} \cdot 6 \mathrm{H}_{2} \mathrm{O}\right)$ were obtained from Acros Organics, and hexachloroplatinic acid $\left(\mathrm{H}_{2} \mathrm{PtCl}_{6} \cdot 6 \mathrm{H}_{2} \mathrm{O}\right)$ was received from Alfa Aesar. Sodium citrate dihydrate $(99+\%$ purity) was received from Aldrich. Tetrahydrofuran (THF, Fisher Scientific) was distilled from $\mathrm{Na} / \mathrm{K}$ in a nitrogen atmosphere. Water was purified by a Nanopure II system to a resistivity of $>18 \mathrm{M} \Omega \mathrm{cm}$. Spectra/ Por 6-8 kD molecular weight cutoff (MWCO) dialysis tubing 
A $\left[\mathrm{Ca}_{2} \mathrm{Nb}_{3} \mathrm{O}_{10}\right]^{-}$
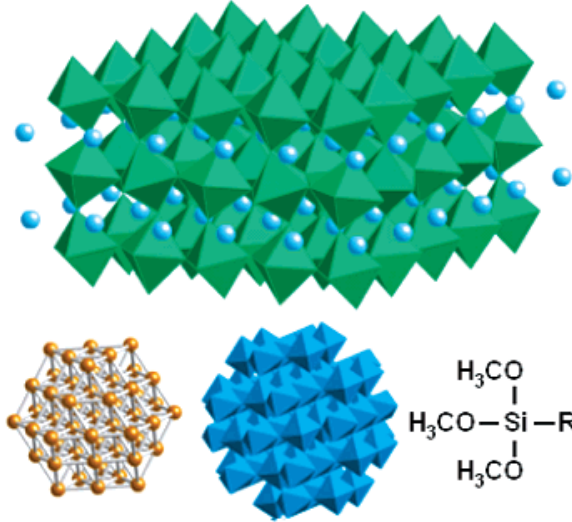

$\mathrm{Pt}$ (cit)

$\mathrm{IrO}_{2}$ (cit)

Linker (L)

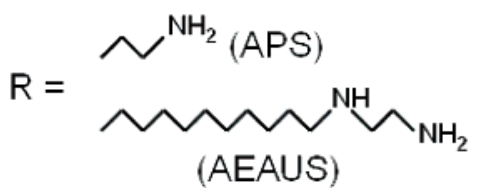

B

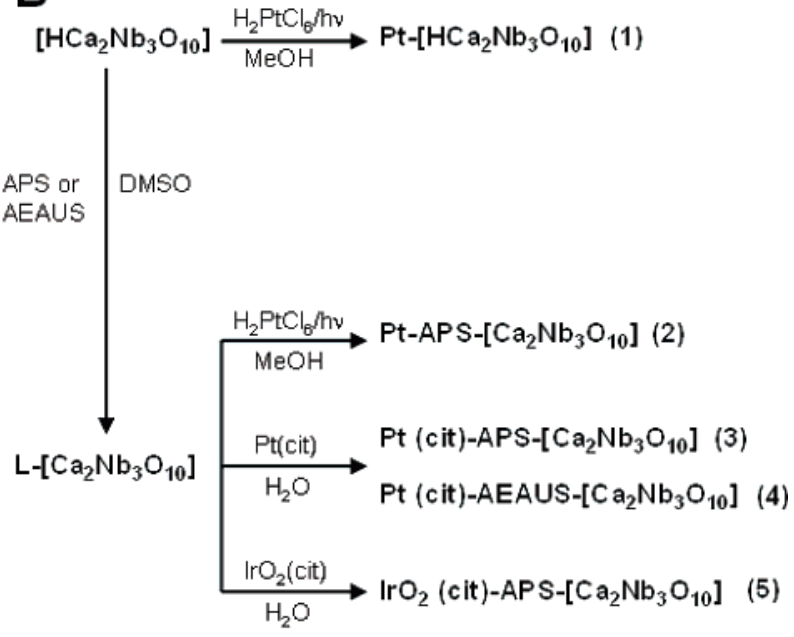

Figure 1. (A) Structures of nanoparticles and organic linkers. (B) Assembly of photocatalysts.

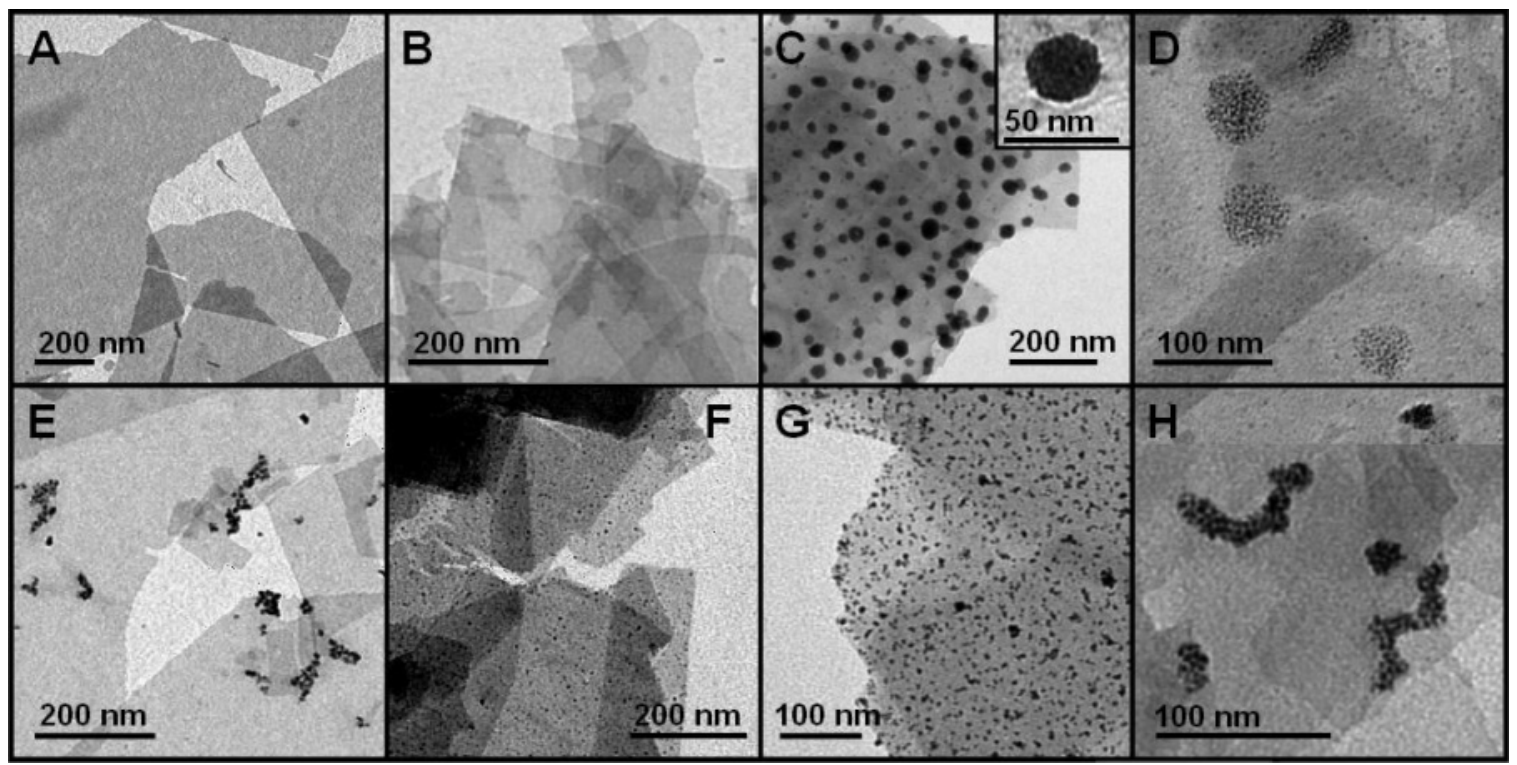

Figure 2. TEM images of (A) exfoliated $\left[\mathrm{HCa}_{2} \mathrm{Nb}_{3} \mathrm{O}_{10}\right]$ nanosheets, (B) APS- $\left[\mathrm{Ca}_{2} \mathrm{Nb}_{3} \mathrm{O}_{10}\right]$, (C) IrO (cit)-APS- $\left[\mathrm{Ca}_{2} \mathrm{Nb}_{3} \mathrm{O}_{10}\right]$ before irradiation, magnified $\mathrm{IrO}_{2}$ cluster in inset, (D) $\mathrm{IrO}_{2}$ (cit)-APS-[Ca $\left.\mathrm{Nb}_{3} \mathrm{O}_{10}\right]$ after irradiation, (E) Pt-[HCa $\left.\mathrm{Nb}_{3} \mathrm{O}_{10}\right]$, (F) Pt-APS-[Ca $\left.\mathrm{Nb}_{3} \mathrm{O}_{10}\right],(\mathrm{G}) \mathrm{Pt}(\mathrm{cit})-\mathrm{APS}-\left[\mathrm{Ca}_{2} \mathrm{Nb} \mathrm{O}_{10}\right]$, and $(\mathrm{H})$ Pt aggregates on Pt-APS- $\left[\mathrm{Ca}_{2} \mathrm{Nb}_{3} \mathrm{O}_{10}\right]$.

was utilized to remove citrate ions during dialysis. A Fisher Scientific Marathon 21000 centrifuge at $13750 \mathrm{rpm}$ was employed for centrifugation.

APS/AEAUS-[C $\left.\mathbf{C a}_{2} \mathbf{N b}_{3} \mathbf{O}_{\mathbf{1 0}}\right]$. The Dion-Jacobsen phase $\mathrm{HCa}_{2}-$ $\mathrm{Nb}_{3} \mathrm{O}_{10}$ was synthesized according to literature procedures. ${ }^{22,23}$ This product was exfoliated by treatment with a 20 mol excess of $\mathrm{TBA}(\mathrm{OH})$, resulting in individually dispersed $\mathrm{TBA}\left[\mathrm{Ca}_{2}-\right.$ $\mathrm{Nb}_{3} \mathrm{O}_{10}$ ] nanosheets. ${ }^{24}$ Exfoliation was verified by TEM (Figure $2 \mathrm{~A})$. As synthesized, the sheets retain approximately $80-85 \%$ of their original protons, which were not replaced by $\mathrm{TBA}^{+} .25$ These remaining protonated sites represent possible locations for $\mathrm{Nb}-\mathrm{O}-\mathrm{Si}$ bond formation. The sheets were functionalized with either APS or AEAUS using a modified procedure from literature. ${ }^{17}$ A $100 \mathrm{mg}$ sample was washed three times with 20 $\mathrm{mL}$ aliquots of THF then washed again three times with anhydrous THF. The washed sheets were added to a solution of $170 \mathrm{mg}$ of APS or $300 \mathrm{mg}$ AEAUS in $6 \mathrm{~mL}$ of anhydrous
DMSO in a $\mathrm{N}_{2}$ atmosphere. The solution was stirred vigorously for $2 \mathrm{~h}$. The product was isolated by centrifugation and washed three times with $20 \mathrm{~mL}$ aliquots of water.

$\mathrm{IrO}_{2}$ (cit) and $\mathbf{P t}($ cit). A $225 \mathrm{~mL}$ solution of a citratestabilized Pt colloid $(3.7 \pm 0.6 \mathrm{~nm})$ was prepared from hexachloroplatinic acid following a published procedure. ${ }^{26,27}$ After the reaction, excess citrate ions were removed from the brown solution by dialysis in $4 \mathrm{~L}$ of water overnight to a conductivity of $0.6 \mu \mathrm{S} \mathrm{cm}{ }^{-1}$. The $\mathrm{IrO}_{2}$ (cit) colloid $(4.7 \pm 0.8$ $\mathrm{nm}, 100 \mathrm{~mL}$ ) was synthesized from potassium hexachloroiridate according to the literature. ${ }^{28,29} \mathrm{IrO}_{2}$ (cit) nanoparticles were generally found as aggregates approximately $35-50 \mathrm{~nm}$ in diameter. Excess citrate ions were removed from the blue solution by overnight dialysis in $4 \mathrm{~L}$ of water to a conductivity of $6.4 \mu \mathrm{S} \mathrm{cm} \mathrm{cm}^{-1}$.

Pt-APS-[Ca $\left.\mathbf{C a}_{2} \mathbf{N b}_{3} \mathbf{O}_{10}\right]$. Platinum nanoparticles were grown on the surface of $\mathrm{TBA}\left[\mathrm{Ca}_{2} \mathrm{Nb}_{3} \mathrm{O}_{10}\right]$ by photodeposition following 
similar procedures. ${ }^{13,15,28}$ A quartz round-bottom flask was filled with $100 \mathrm{~mL}$ of water and $20 \mathrm{~mL}$ of methanol. A sample of $100 \mathrm{mg}$ of either APS-functionalized or nonfunctionalized nanosheets was dispersed in this solution and $3 \mathrm{wt} \%$ (based on nanosheets) of hexachloroplatinic acid was also dissolved into it. The reaction mixture was stirred in an $\mathrm{Ar}$ atmosphere and irradiated for $1 \mathrm{~h}$, depositing $\mathrm{Pt}$ nanoparticles onto the surface of the nanosheets. The final nanosheet suspension was metallic gray in absence of APS and brown in functionalized samples. The product was collected by centrifugation and washed twice with $50 \mathrm{~mL}$ aliquots of water.

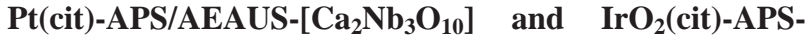
$\left[\mathrm{Ca}_{2} \mathbf{N b}_{3} \mathrm{O}_{10}\right]$. Citrate-coated nanoparticles were attached to APS- (or AEAUS)-functionalized nanosheets by adding a 10 $\mathrm{mL}$ aqueous solution containing $100 \mathrm{mg}$ of the-functionalized nanosheets to a $40 \mathrm{~mL}$ aqueous solution containing $3 \mathrm{wt} \%$ (based on nanosheets) of the respective colloid and bringing the final solution volume to $50 \mathrm{~mL}$. The reaction mixture was stirred for $2 \mathrm{~h}$ at room temperature. The product was isolated by centrifugation and washed twice with $50 \mathrm{~mL}$ aliquots of water.

Photocatalytic $\mathbf{H}_{\mathbf{2}}$ Evolution Experiments. Irradiation was performed at $30{ }^{\circ} \mathrm{C}$ using four $175 \mathrm{~W}$ low-pressure mercury lamps surrounding a $100 \mathrm{~mL}$ quartz flask. A quantum flux of $5.82 \times 10^{-7} \mathrm{~mol} / \mathrm{s}$ was measured in the flask by ferrioxalate actinometry. ${ }^{30}$ The flask was filled with $50 \mathrm{~mL}$ of water containing $100 \mathrm{mg}$ of the respective catalysts and connected to a gas chromatography system. The flask was evacuated and purged four times with argon gas, and the stirred mixture was then irradiated for $5 \mathrm{~h}$ with periodic removal of gas samples. Gas samples were analyzed with a Varian gas chromatograph employing a Supelco molecular 60/80 sieve 5A column with Ar as the carrier gas and a thermal conductivity detector (TCD).

XPS Sample Preparation. Samples for X-ray photoelectron spectroscopy (XPS) measurements were prepared by dropcasting a concentrated solution of $\mathrm{IrO}_{2}$ (cit)-APS- $\left[\mathrm{Ca}_{2} \mathrm{Nb}_{3} \mathrm{O}_{10}\right]$ onto a silicon wafer substrate. The sample was then inserted into an UHV chamber maintained at a base pressure less than $10^{-9}$ Torr where XPS spectra were collected.

Electrochemical Measurements. Electrochemical measurements were conducted with a Perkin-Elmer Model 263A potentiostat and a three-electrode system consisting of a gold disk working electrode, a saturated calomel (SCE) reference electrode, and a Ag wire as the auxiliary electrode. A degassed 1.0 $\mathrm{M}$ aqueous $\mathrm{NaOH}$ solution served as the electrolyte. The system was calibrated with the potential of the $\left[\mathrm{Fe}(\mathrm{CN})_{6}\right]^{4-13-}$ couple $(+0.358 \mathrm{~V}$ versus NHE in water). All potentials are quoted versus NHE. Measurements were performed at $100 \mathrm{mV} /$ s. Individual catalysts were mounted on the Au disk electrode as thin films by coating the electrode with a drop of the catalyst suspension and by drying in the $\mathrm{N}_{2}$ atmosphere of a glove box.

Other Measurements. UV/vis spectra were collected using an Ocean Optics DH2000 light source and HR2000 CG-UVNIR spectrometer. Infrared spectra were collected with a Galaxy Series FT-IR spectrophotometer from Mattson. Electron micrographs were obtained using a Philips CM120 transmission electron microscope and a Gatan MegaScan digital camera. XPS spectra were collected using an $\mathrm{Al} \mathrm{K} \alpha(\mathrm{h} v=1486.6 \mathrm{eV}) \mathrm{X}$-ray source with a Vacuum Generators VG100AX electron analyzer operating at a pass energy of $20 \mathrm{eV}$.

\section{Results and Discussion}

Figure 1 gives an overview over the synthesis of the catalysts and the structures of the nanoparticle building blocks. Reaction

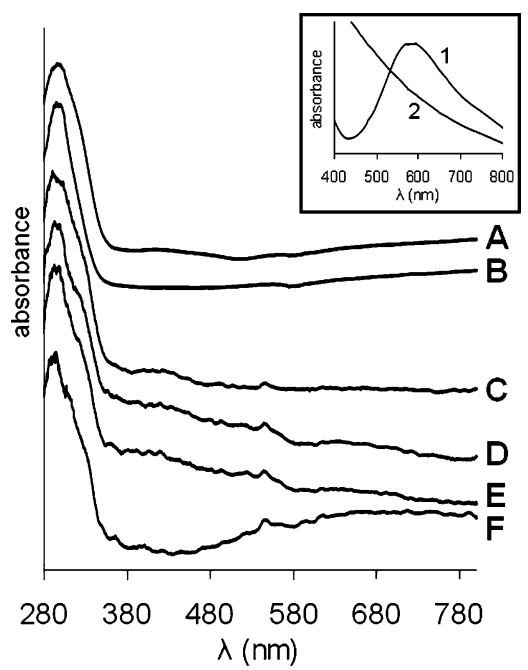

Figure 3. Diffuse reflectance $\mathrm{UV}-$ vis spectra for all species containing nanosheets of (A) exfoliated $\left[\mathrm{HCa}_{2} \mathrm{Nb}_{3} \mathrm{O}_{10}\right]$ nanosheets, (B) Pt-[HCa $\mathrm{HC}_{2}$ $\left.\mathrm{Nb}_{3} \mathrm{O}_{10}\right]$, (C) APS-[Ca $\left.\mathrm{Cb}_{3} \mathrm{O}_{10}\right]$, (D) Pt-APS- $\left[\mathrm{Ca}_{2} \mathrm{Nb}_{3} \mathrm{O}_{10}\right]$, (E) Pt(cit)APS-[Ca $\left.\mathrm{Nb}_{3} \mathrm{O}_{10}\right]$, and (F) $\mathrm{IrO}_{2}$ (cit)-APS-[Ca $\mathrm{Ca}_{2} \mathrm{Nb}_{10}$ ]. Inset: Absorption UV-vis spectra of (1) $\mathrm{IrO}_{2}$ (cit) colloid in solution and (2) $\mathrm{Pt}$ (cit) colloid in solution.

of exfoliated $\mathrm{TBA}_{x}\left[\mathrm{H}_{1-x} \mathrm{Ca}_{2} \mathrm{Nb}_{3} \mathrm{O}_{10}\right]$ nanosheets $(x=0.15-0.20$, hereafter referred to as $\left[\mathrm{HCa}_{2} \mathrm{Nb}_{3} \mathrm{O}_{10}\right]$ or $\mathrm{TBA}\left[\mathrm{Ca}_{2} \mathrm{Nb}_{3} \mathrm{O}_{10}\right]$ for brevity) with 3-aminopropyltrimethoxysilane (APS) or $\mathrm{N}$-(2aminoethyl)-11-aminoundecyltrimethoxysilane (AEAUS) in DMSO forms amino-terminated nanosheets $\mathrm{L}-\left[\mathrm{Ca}_{2} \mathrm{Nb}_{3} \mathrm{O}_{10}\right]$. On the basis of coulometric titration with trinitrobenzenesulfonic acid, this material contains $0.43 \pm 0.06$ linker molecules per $\left[\mathrm{Ca}_{2} \mathrm{Nb}_{3} \mathrm{O}_{10}\right]$ unit. ${ }^{17}$ The reaction is accompanied by partial restacking of the nanosheets (TEMs in Figure 2A,B), which is probably driven by $\mathrm{H}$-bonding between the primary amines. There are two ways of coupling Pt nanoparticles to the APSmodified nanosheets. Pt particles can be grown photochemically by irradiation of an aqueous mixture of the APS- $\left[\mathrm{Ca}_{2} \mathrm{Nb}_{3} \mathrm{O}_{10}\right]$ with $\mathrm{H}_{2} \mathrm{PtCl}_{6}$ in the presence of methanol, or alternatively preformed citrate-coated $\mathrm{Pt}$ nanoparticles can be attached by adding a suspension of the APS- $\left[\mathrm{Ca}_{2} \mathrm{Nb}_{3} \mathrm{O}_{10}\right]$ to a citrate stabilized Pt sol in water. TEM data (Figure $2 \mathrm{~F}, \mathrm{G}$ ) shows that in both cases Pt particles are homogeneously distributed over the entire sheet surface, indicating that the APS groups provide good linkage sites for the nanoparticles. Approximately 9000 Pt nanoparticles per $\mu \mathrm{m}^{2}$ are attached with an estimated mass percent of 5.1. The size of the Pt particles is very similar for coupling $(3.7 \pm 0.6 \mathrm{~nm})$ and growth pathways $(4.46 \pm 0.78$ $\mathrm{nm})$. By adding the $\mathrm{Pt}(\mathrm{cit})$ colloid to a stirred nanosheet dispersion, that is, by reversing the order of addition, it is also possible to deposit $\mathrm{Pt}$ (cit) particles in the form of $\sim 20 \mathrm{~nm}$ large aggregates of 20-40 individual nanoparticles (Figure $2 \mathrm{H}$ ). Occasionally, these clusters fuse together to form clusters up to $100 \mathrm{~nm}$ in length. On the contrary, if Pt(cit) linkage is attempted in the absence of a linker, no particle attachment to the nanosheets takes place. When Pt nanoparticles are photochemically grown on $\mathrm{TBA}\left[\mathrm{Ca}_{2} \mathrm{Nb}_{3} \mathrm{O}_{10}\right]$ nanosheets not equipped with a linker, large clustered $\mathrm{Pt}$ nanoparticles form at the periphery of the sheets (Figure 2E) as described earlier. ${ }^{15}$

Iridium dioxide-modified nanosheets were synthesized by adding an APS- $\left[\mathrm{Ca}_{2} \mathrm{Nb}_{3} \mathrm{O}_{10}\right]$ suspension to a solution of citratecoated $\mathrm{IrO}_{2}$ nanoparticles, which was prepared according to the literature. ${ }^{21,28}$ The TEM in Figure 2C shows that the $\mathrm{IrO}_{2}$ (cit) nanoparticles form globular clusters on the nanosheets that are $\sim 30 \mathrm{~nm}$ in diameter. These clusters, which are also present in 


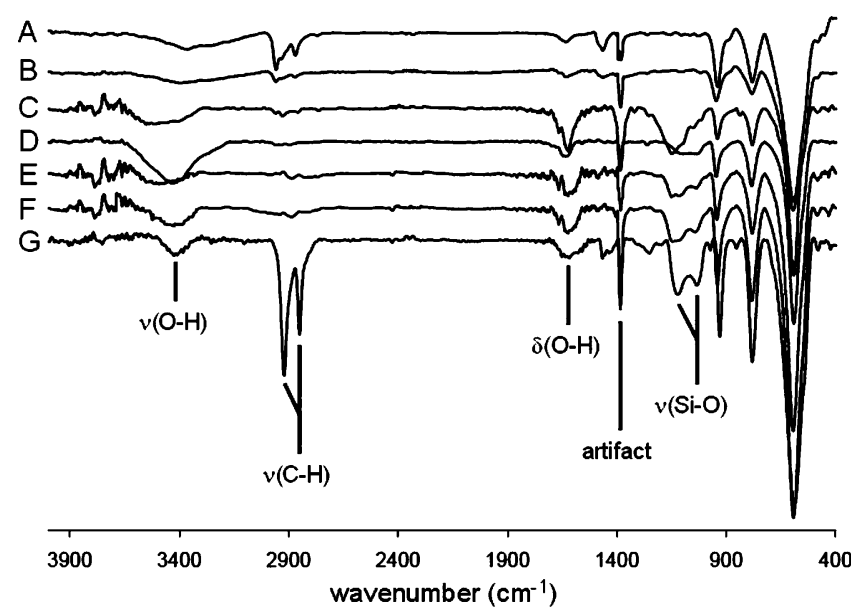

Figure 4. Infrared spectra of (A) exfoliated $\left[\mathrm{HCa}_{2} \mathrm{Nb}_{3} \mathrm{O}_{10}\right]$ nanosheets, (B) Pt-[ $\left[\mathrm{HCa}_{2} \mathrm{Nb}_{3} \mathrm{O}_{10}\right]$, (C) APS-[ $\left.\mathrm{Ca}_{2} \mathrm{Nb}_{3} \mathrm{O}_{10}\right]$, (D) Pt-APS- $\left[\mathrm{Ca}_{2} \mathrm{Nb}_{3} \mathrm{O}_{10}\right]$, (E) $\mathrm{IrO}_{2}$ (cit)-APS- $\left[\mathrm{Ca}_{2} \mathrm{Nb}_{3} \mathrm{O}_{10}\right]$, (F) Pt(cit)-APS- $\left[\mathrm{Ca}_{2} \mathrm{Nb}_{3} \mathrm{O}_{10}\right]$, and $(\mathrm{G})$ AEAUS- $\left[\mathrm{Ca}_{2} \mathrm{Nb}_{3} \mathrm{O}_{10}\right]$.

the $\mathrm{IrO}_{2}$ colloidal starting material, are supported by bridging citrate groups. ${ }^{21}$

Optical spectra for all compounds, collected by diffuse reflectance UV-vis spectroscopy, are presented in Figure 3. Band edge absorption begins at $350 \mathrm{~nm}$ for all species in accordance with a band gap of $3.53 \mathrm{eV}$ for the TBA[Ca $\left.\mathrm{Ca}_{2} \mathrm{Nb}_{3} \mathrm{O}_{10}\right]$ nanosheet semiconductors. ${ }^{15}$ For $\mathrm{IrO}_{2}$ (cit)-APS- $\left[\mathrm{Ca}_{2} \mathrm{Nb}_{3} \mathrm{O}_{10}\right]$, a broad absorption band at $650 \mathrm{~nm}$ (spectrum $\mathrm{F}$ ) is observed that gives the material a blue color. The absorption is caused by the $\mathrm{IrO}_{2}$ (cit) nanoparticles (inset in Figure 3), ${ }^{28}$ suspensions of which appear deep blue due to a $\mathrm{Ir}^{4+} \mathrm{d}-\mathrm{d}$ transition. ${ }^{31}$ The spectra for Pt-APS- $\left[\mathrm{Ca}_{2} \mathrm{Nb}_{3} \mathrm{O}_{10}\right]$ with grown or deposited Pt nanoparticles have a broad absorption at $380-580 \mathrm{~nm}$ that gives the material a brown appearance. The same color is also observed in the citrate-stabilized Pt sol that served as the starting material in the Pt coupling reaction (inset in Figure 3). ${ }^{27}$ If platinum is grown on the nonfunctionalized nanosheets, this absorption is absent (spectrum B), and the material appears metallic gray instead. This behavior is due to the presence of $150 \mathrm{~nm}$ large Pt clusters that resemble bulk Pt metal.

Infrared (IR) spectra for each species are shown in Figure 4. For all APS-modified nanosheets, absorption peaks at 1159 and $1064 \mathrm{~cm}^{-1}$ reveal the presence of $\mathrm{Si}-\mathrm{O}$ bonds that are due to the APS attachment. A peak at $1652 \mathrm{~cm}^{-1}$ is assigned to $\mathrm{O}-\mathrm{H}$ bonds from either $\mathrm{Si}-\mathrm{OH}$ or water. Compared to the unmodified nanosheets, the band from $\mathrm{C}-\mathrm{H}$ bonds at 2973 and $2879 \mathrm{~cm}^{-1}$ are less intense in the APS-functionalized samples. This suggests loss of $\mathrm{TBA}^{+}$in the functionalization step. The weak remaining signal is due to methylene groups from APS. Because of the longer aliphatic chain length of the AEAUS ligand, these bands are increased in spectrum $\mathrm{G}$. Bands for the carboxylate ions of the citrate surfactant would appear at $\sim 1600$ and $1400 \mathrm{~cm}^{-1} 32$ but are obscured by $\mathrm{O}-\mathrm{H}$ and $\mathrm{Si}-\mathrm{O}$ vibrational modes as discussed above.

Photocatalytic studies of all materials were carried out as described in the experimental section. Time-resolved plots for $\mathrm{H}_{2}$ evolution are presented in Figure 5, while numerical data are shown in Table 1. Apparent quantum efficiencies $(\mathrm{QE}=$ $2 \cdot\left[\mathrm{H}_{2}\right] / I$ ) were calculated from the mean $\mathrm{H}_{2}$ evolution rate (mol/ s) and the quantum flux $(I)$ of the irradiation system. The pure exfoliated $\left[\mathrm{HCa}_{2} \mathrm{Nb}_{3} \mathrm{O}_{10}\right]$ nanosheets evolve $\mathrm{H}_{2}$ at a rate of 1.75 $\mu \mathrm{mol} / \mathrm{h}(\mathrm{QE}=0.17 \%)$ at $\mathrm{pH} 10.8 .{ }^{15}$ Functionalization with APS slightly increases the catalytic activity of the sheets to 2.15 $\mu \mathrm{mol} / \mathrm{h}(\mathrm{QE}=0.21 \%)$ at $\mathrm{pH} 10.2$. This increase is significant

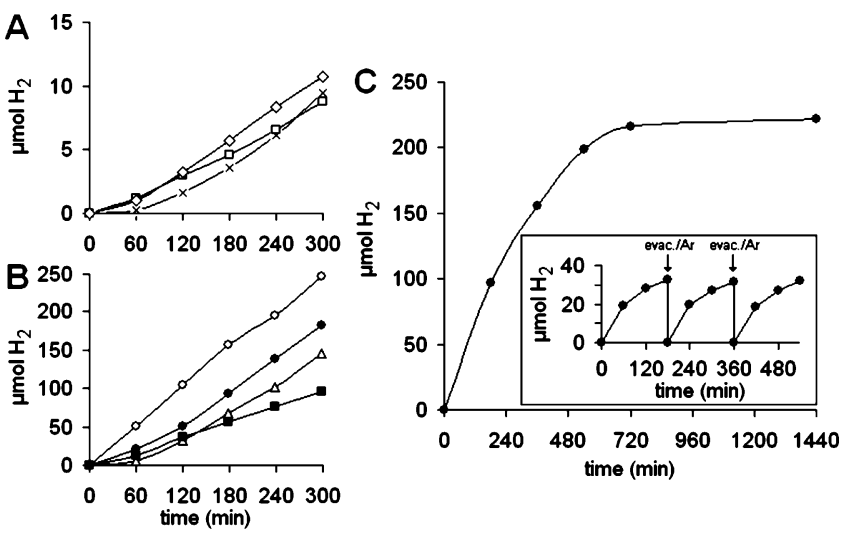

Figure 5. Time-resolved $\mathrm{H}_{2}$ evolution data for (A) APS- $\left[\mathrm{Ca}_{2} \mathrm{Nb}_{3} \mathrm{O}_{10}\right]$ $(\diamond), \mathrm{IrO}_{2}$ (cit)-APS- $\left[\mathrm{Ca}_{2} \mathrm{Nb}_{3} \mathrm{O}_{10}\right](\times)$, exfoliated $\left[\mathrm{HCa}_{2} \mathrm{Nb}_{3} \mathrm{O}_{10}\right](\square),(\mathrm{B})$ Pt- $\left[\mathrm{HCa}_{2} \mathrm{Nb}_{3} \mathrm{O}_{10}\right](\mathrm{O})$, Pt-APS- $\left[\mathrm{Ca}_{2} \mathrm{Nb}_{3} \mathrm{O}_{10}\right](-)$, Pt(cit)-APS-[Ca ${ }_{2}-$ $\left.\mathrm{Nb}_{3} \mathrm{O}_{10}\right](\triangle), \mathrm{Pt}(\mathrm{cit})$-AEAUS- $\left[\mathrm{Ca}_{2} \mathrm{Nb}_{3} \mathrm{O}_{10}\right](\mathbf{\square})$, and (C) Time-resolved $\mathrm{H}_{2}$ evolution from $\mathrm{Pt}-\left[\mathrm{HCa}_{2} \mathrm{Nb}_{3} \mathrm{O}_{10}\right]$ showing deactivation of catalyst. Inset: data collected after evacuating flask and purging with Ar to partially restore activity.

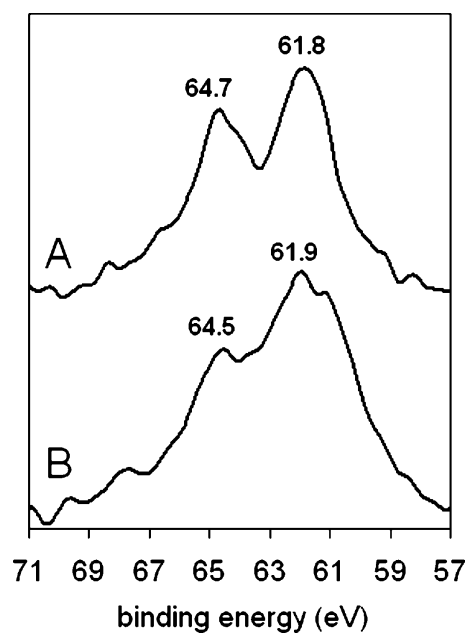

Figure 6. XPS spectra of the $4 \mathrm{f}_{5 / 2}$ and $4 \mathrm{f}_{7 / 2}$ peaks of Ir collected from $\mathrm{IrO}_{2}$ (cit)-APS-[Ca $\left.\mathrm{Ca}_{3} \mathrm{O}_{10}\right]$; (A) before and (B) after irradiation.

(the error margin of the experiment is $0.04 \%$ based on repeated runs) and indicates that the primary $\mathrm{NH}_{2}$ groups of the linker molecules can act as sacrificial electron donors in this system. Butylamine has been previously shown to be an effective electron donor under similar conditions. ${ }^{33,34}$ When 3 wt \% Pt nanoparticles are directly grown onto exfoliated $\left[\mathrm{HCa}_{2} \mathrm{Nb}_{3} \mathrm{O}_{10}\right]$, the catalytic activity of the material increases to $49.2 \mu \mathrm{mol} / \mathrm{h}$ $(\mathrm{QE}=4.69 \%)$ at $\mathrm{pH} 10.6 .{ }^{15}$ Compared to this, the activity of photochemically grown Pt-APS- $\left[\mathrm{Ca}_{2} \mathrm{Nb}_{3} \mathrm{O}_{10}\right](36.6 \mu \mathrm{mol} / \mathrm{h}, \mathrm{QE}$ $=3.49 \%$ at $\mathrm{pH} 9.9)$ is $25 \%$ lower. The reduction in catalytic activity occurs even though the Pt content is higher than in the material without linker. On the basis of TEM, there are $~ 3500$ nanoparticles per $\mu \mathrm{m}^{2}$ providing an estimated mass percent of 4.7, compared to $3 \%$ for $\mathrm{Pt}-\left[\mathrm{HCa}_{2} \mathrm{Nb}_{3} \mathrm{O}_{10}\right]$. The reduced activity of Pt-APS- $\left[\mathrm{Ca}_{2} \mathrm{Nb}_{3} \mathrm{O}_{10}\right]$ suggests that the linker diminishes electronic contact between the metal and the semiconductor. Monolayers on Pt that contained APS groups have indeed been shown to decrease electron transfer across the interface. ${ }^{35}$

A further reduction in $\mathrm{H}_{2}$ evolution rate occurs in $\mathrm{Pt}(\mathrm{cit})$ APS- $\left[\mathrm{Ca}_{2} \mathrm{Nb}_{3} \mathrm{O}_{10}\right]$, where $\mathrm{Pt}(\mathrm{cit})$ particles were assembled onto the APS groups and not grown as in the previous material. The activity $(29.1 \mu \mathrm{mol} / \mathrm{h}, \mathrm{QE}=2.78 \%$ at $\mathrm{pH} 9.9)$ of this catalyst is $20 \%$ lower than the photochemically grown material, but still higher than the bare nanosheets without Pt. The decrease in catalytic activity is possibly due to the citrate-capping ligand, 
TABLE 1: $\mathrm{H}_{2}$ Evolution Data

\begin{tabular}{lccccccc}
\hline & {$\left[\mathrm{HCa}_{2} \mathrm{Nb}_{3} \mathrm{O}_{10}\right]^{15}$} & $\begin{array}{c}\mathrm{APS}- \\
{\left[\mathrm{Ca}_{2} \mathrm{Nb}_{3} \mathrm{O}_{10}\right]}\end{array}$ & $\left.\begin{array}{c}\mathrm{Pt}- \\
{\left[\mathrm{HCa}_{2} \mathrm{Nb}_{3} \mathrm{O}_{10}\right]}\end{array}\right]^{15}$ & $\begin{array}{c}\text { Pt-APS- } \\
{\left[\mathrm{Ca}_{2} \mathrm{Nb}_{3} \mathrm{O}_{10}\right]}\end{array}$ & $\begin{array}{c}\mathrm{Pt}(\mathrm{cit})-\mathrm{APS}- \\
{\left[\mathrm{Ca}_{2} \mathrm{Nb}_{3} \mathrm{O}_{10}\right]}\end{array}$ & $\begin{array}{c}\text { Pt(cit)-AEAUS- } \\
{\left[\mathrm{Ca}_{2} \mathrm{Nb}_{3} \mathrm{O}_{10}\right]}\end{array}$ & $\begin{array}{c}\text { IrO } \\
{\left[\mathrm{Ca}_{2} \mathrm{Nb}_{3} \mathrm{O}_{10}\right]}\end{array}$ \\
\hline $\mathrm{pH}$ & 10.8 & 10.2 & 10.6 & 9.9 & 9.9 & 10.1 & 9.9 \\
$\mathrm{H}_{2}[\mu \mathrm{mol}]$ after $5 \mathrm{~h}$ & 8.77 & 10.77 & 245.73 & 182.84 & 145.50 & 96.51 & 9.42 \\
$\mathrm{H}_{2}$ rate $[\mu \mathrm{mol} / \mathrm{h}]$ & 1.75 & 2.15 & 49.15 & 36.57 & 29.10 & 19.30 & 1.88 \\
$\mathrm{QE}[\%]$ & 0.17 & 0.21 & 4.69 & 3.49 & 2.78 & 1.84 & 0.18
\end{tabular}

TABLE 2: Binding Energy Values (eV)

\begin{tabular}{|c|c|c|c|c|c|c|}
\hline & $\mathrm{Ir}^{045}$ & $\mathrm{Ir}^{3+45}$ & $\mathrm{Ir}^{4+45}$ & $\begin{array}{c}\text { Reagent } \\
\text { grade } \mathrm{IrO}_{2}\end{array}$ & $\begin{array}{c}\text { pre-irradiation } \\
\mathrm{IrO}_{2} \text { (cit)-APS- } \\
{\left[\mathrm{Ca}_{2} \mathrm{Nb}_{3} \mathrm{O}_{10}\right]}\end{array}$ & $\begin{array}{c}\text { post-irradiation } \\
\mathrm{IrO}_{2} \text { (cit)-APS- } \\
{\left[\mathrm{Ca}_{2} \mathrm{Nb}_{3} \mathrm{O}_{10}\right]}\end{array}$ \\
\hline $4 f_{5 / 2}$ & 63.8 & 64.8 & 66.5 & 64.8 & 64.7 & 64.5 \\
\hline $4 f_{7 / 2}$ & 61.0 & 62.0 & 63.7 & 62.0 & 61.8 & 61.9 \\
\hline
\end{tabular}

which reduces the substrate-accessible surface area on the Pt nanoparticles. To further investigate the effect of the linker, we attached AEAUS to the nanosheets and tested $\mathrm{H}_{2}$ evolution activity after attaching $5.3 \%$ (mass) of citrate-coated Pt. A monolayer of AEAUS on $\mathrm{SiO}_{2}$ has a thickness of $2.4 \pm 0.2$ $\mathrm{nm},{ }^{36}$ compared to $0.5 \mathrm{~nm}$ for APS. ${ }^{37}$ With an activity of 19.3 $\mu \mathrm{mol} / \mathrm{h}(\mathrm{QE}=1.84 \%)$ at $\mathrm{pH} 10.1$, the AEAUS-supported catalyst evolved the lowest amount of $\mathrm{H}_{2}$ among Pt-containing catalysts, further suggesting a correlation between catalytic activity and the distance that electrons must travel between nanosheet and cocatalyst.

None of the catalysts evolved measurable quantities of $\mathrm{O}_{2}$ during irradiation. This raises the question about the source of the electrons in the system. On the basis of experiments with variable concentrations of $\mathrm{TBA}(\mathrm{OH})$, we can rule out that tetrabutylammonium is the reducing agent. Increasing the TBA concentration in solution 450 -fold to a final concentration of $0.4 \mathrm{mmol} / \mathrm{L}$ increases the $\mathrm{H}_{2}$ evolution rate only by $15 \%$ (to $1.9 \mu \mathrm{mol} / \mathrm{h}$ ). This effect is very small compared to other systems with sacrificial reagents, for example, EDTA/TiO ${ }_{2}^{38,39}$ or $\mathrm{Na}_{2}$ $\mathrm{SO}_{3} / \mathrm{CdS},{ }^{40}$ where simple doubling of the reagent concentrations leads to $\mathrm{H}_{2}$ rate increase of $70-100 \%$. Instead, we attribute the observed $15 \%$ rate increase to the presence of small concentrations of primary amines in the TBA $(\mathrm{OH})$ solution. Butylamine, a capable reducing agent, is known to be an impurity in TBA$(\mathrm{OH}) .{ }^{41}$ However, its concentration is too small $(0.05 \%$ based on ninhydrin test) to account for all the observed hydrogen, especially in the experiments without added TBA.

On the basis of data that will be reported in a separate manuscript, we believe that the catalysts are indeed capable of oxidizing water. Oxygen is not detected above the catalyst suspension because of rapid adsorption of oxygen species to the catalysts surface, as has been postulated for other layered niobates and $\mathrm{TiO}_{2}$ under irradiation. ${ }^{14,42,43}$ Eventually, this $\mathrm{O}_{2}$ adsorption shuts down $\mathrm{H}_{2}$ evolution from the catalysts. For the catalysts studied here, activities begin to drop after $9 \mathrm{~h}$ of constant irradiation, as shown for Pt- $\left[\mathrm{HCa}_{2} \mathrm{Nb}_{3} \mathrm{O}_{10}\right]$ in Figure 5C. However, the activity can be restored to $>60 \%$ by evacuating the system and purging it with Ar. This seems to remove some, but not all, of the adsorbed $\mathrm{O}_{2}$ species from the catalyst surface.

For $\mathrm{KCa}_{2} \mathrm{Nb}_{3} \mathrm{O}_{10}$, it has recently been demonstrated that stoichiometric but low $\mathrm{H}_{2} / \mathrm{O}_{2}$ evolution from water is possible when the catalysts are modified with $\mathrm{RuO}_{2} \cdot{ }^{14}$ We attempted to achieve similar reactivity using $\mathrm{IrO}_{2}$ (cit) nanoparticles as cocatalysts for the nanosheets. Iridium dioxide is known to be a highly active water oxidation catalyst ${ }^{20}$ and can be prepared in colloidal form via hydrolysis of $\mathrm{K}_{2} \mathrm{IrCl}_{6}$ in the presence of citrate. ${ }^{21}$ Linkage to the nanosheets produces $\mathrm{IrO}_{2}$ (cit)-APS$\left[\mathrm{Ca}_{2} \mathrm{Nb}_{3} \mathrm{O}_{10}\right]$ as described above. Under UV irradiation, the compound does not evolve $\mathrm{O}_{2}$ from water. Instead, it produces $\mathrm{H}_{2}$ at rates comparable to Pt-free nanosheet catalysts (Figure 5A). During photolysis, the color of the catalyst also gradually changes from blue to white. Because the blue color of $\mathrm{IrO}_{2}$ (cit) nanoparticles is attributed to a $\mathrm{d}-\mathrm{d}$ transition of $\mathrm{Ir}^{4+}, 31$ this optical change indicates a change of the $\mathrm{Ir}^{4+}$ oxidation state. Photobleaching can be ruled out, because disappearance of the blue color is permanent. TEM data of the catalyst (Figure 2D) after irradiation confirms a change of the $\mathrm{IrO}_{2}$ (cit) material. Only flat islands of smaller particles can be observed in place of the globular $\mathrm{IrO}_{2}$ (cit) clusters of the original catalyst (Figure 2C). To determine the iridium oxidation state in these islands, XPS spectra were recorded for samples before and after irradiation. The data in Figure 6 was calibrated to the $\mathrm{O}$ 1s peak of $\mathrm{Nb}_{2} \mathrm{O}_{5} \cdot{ }^{44}$ A linear background was removed from the data, which was then submitted to Gaussian fitting to minimize noise in the signal. Binding energy values are tabulated in Table 2 along with literature values for Ir. Spectrum A of the pre-irradiated $\mathrm{IrO}_{2}$ (cit)-APS- $\left[\mathrm{Ca}_{2} \mathrm{Nb}_{3} \mathrm{O}_{10}\right]$ shows two peaks with binding energies at 64.7 and $61.8 \mathrm{eV}$ for the $4 \mathrm{f}_{5 / 2}$ and $4 \mathrm{f}_{7 / 2}$ peaks, respectively, and a saddle at relatively high intensity. The spectrum compares well with that of Hara et al. for reagent grade $\mathrm{IrO}_{2},{ }^{45}$ which was interpreted by the authors as belonging to a mixture of $\mathrm{Ir}^{4+}$ and $\mathrm{Ir}^{3+}$ (as $\mathrm{Ir}_{2} \mathrm{O}_{3}$ impurity). Thus, $\mathrm{IrO}_{2}$ (cit)APS- $\left[\mathrm{Ca}_{2} \mathrm{Nb}_{3} \mathrm{O}_{10}\right]$ contains a mixture of $\mathrm{IrO}_{2}$ and $\mathrm{Ir}_{2} \mathrm{O}_{3}$, which is in agreement with previous studies on the Ir-oxidation state in $\mathrm{IrO}_{2}$ (cit) nanoparticles. ${ }^{31,46}$

After irradiation (spectrum B), the $4 \mathrm{f}_{7 / 2}$ peak shifted slightly to $61.9 \mathrm{eV}$ and was significantly broadened with a small peak on the shoulder at approximately $61.1 \mathrm{eV}$. The $4 \mathrm{f}_{5 / 2}$ peak was shifted to $64.5 \mathrm{eV}$, opposite in direction from the $4 \mathrm{f}_{7 / 2}$ shift, and appeared at lower intensity. The saddle between these two peaks was at very high intensity, nearly obscuring the $4 \mathrm{f}_{5 / 2}$ peak and contained a small bump centered at $63.6 \mathrm{eV}$. Although the new features in spectrum $B$ could in principle be due to noise, both peak fitting and minimal noise in those regions in spectrum A make this unlikely. Instead, we attribute the new features to the $4 \mathrm{f}_{5 / 2}$ and $4 \mathrm{f}_{7 / 2}$ peaks of $\operatorname{Ir}(0)$, which appear at 63.8 and 61.0 $\mathrm{eV}$, that is, very close to the new features in spectrum B. ${ }^{45}$ These peaks in summation with spectrum $A$ can produce a spectrum similar to B when the intensity of the signals are varied, based upon the extent of reduction. Fitting the observed spectrum $B$ with the theoretical data suggests that $10-20 \%$ of the $\mathrm{IrO}_{2}$ in $\mathrm{IrO}_{2}$ (cit)-APS- $\left[\mathrm{Ca}_{2} \mathrm{Nb}_{3} \mathrm{O}_{10}\right]$ was reduced to $\mathrm{Ir}(0)$. A similar photochemical reduction has been previously observed for a $\mathrm{IrO}_{2}$ colloid. ${ }^{28}$

To obtain further insight into the function of the catalysts, cyclic voltammetry was used to determine the onset potentials for water oxidation and reduction in aqueous $1.0 \mathrm{M} \mathrm{NaOH}$. For this purpose, thin films of the catalysts were deposited onto an 

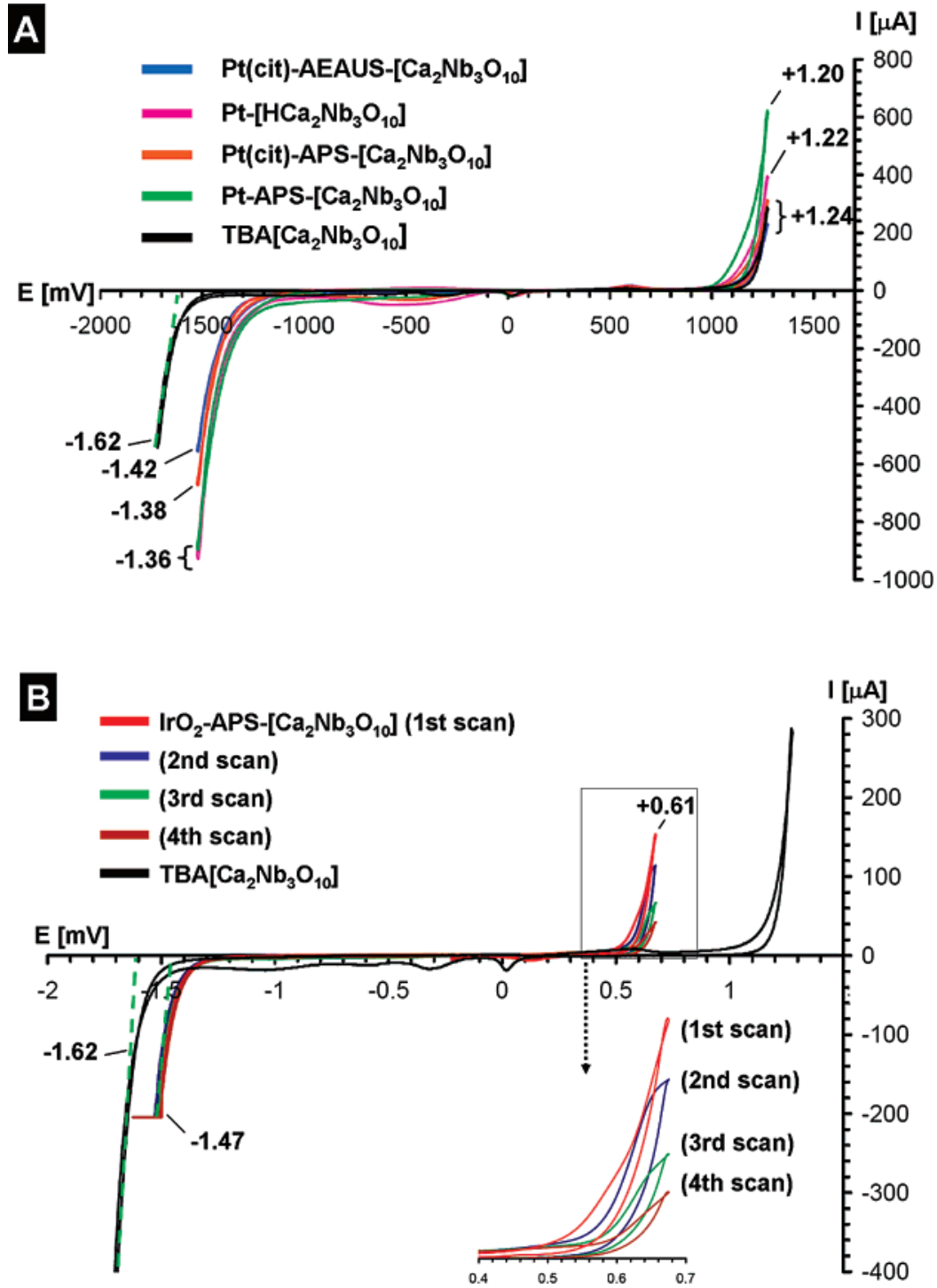

Figure 7. Cyclic voltammograms for nanosheet catalysts. (A) Pt-based structures and (B) $\mathrm{IrO}_{2}$-based structures (inset shows magnified view of 0.4-0.7 V potential interval). All potentials are quoted vs NHE. Onset potentials for water oxidation and reduction were determined graphically from the intercept of a linear fit of the current with $x$-axis (shown for the $\mathrm{H}_{2} \mathrm{O}$ reduction potential of $\mathrm{TBA}\left[\mathrm{Ca}_{2} \mathrm{Nb}_{3} \mathrm{O}_{10}\right]$ ).

TABLE 3: Water Redox Potentials for Catalysts

\begin{tabular}{lcc}
\hline \multicolumn{1}{c}{ sample } & $E\left(\mathrm{H}_{2} \mathrm{O} / \mathrm{H}_{2}\right) / \mathrm{V}$ & $E\left(\mathrm{O}_{2} / \mathrm{HO}^{-}\right) / \mathrm{V}$ \\
\hline$\left[\mathrm{HCa}_{2} \mathrm{Nb}_{3} \mathrm{O}_{10}\right]$ & -1.62 & +1.24 \\
$\mathrm{Pt}-\left[\mathrm{HCa}_{2} \mathrm{Nb}_{3} \mathrm{O}_{10}\right]$ & -1.36 & +1.22 \\
$\mathrm{Pt}-\mathrm{APS}-\left[\mathrm{Ca}_{2} \mathrm{Nb}_{3} \mathrm{O}_{10}\right]$ & -1.36 & +1.20 \\
$\mathrm{Pt}(\mathrm{cit})-\mathrm{APS}-\left[\mathrm{Ca}_{2} \mathrm{Nb}_{3} \mathrm{O}_{10}\right]$ & -1.38 & +1.24 \\
$\mathrm{Pt}(\mathrm{cit})-\mathrm{AEAUS}-\left[\mathrm{Ca}_{2} \mathrm{Nb}_{3} \mathrm{O}_{10}\right]$ & -1.42 & +1.24 \\
$\mathrm{IrO}$ (cit)-APS-[Ca $\left.\mathrm{Cb}_{3} \mathrm{O}_{10}\right]$ & -1.47 & +0.61 \\
$\mathrm{Au}$ disk electrode (unmodified) & -1.62 & +1.24
\end{tabular}

Au disk electrode by drop casting from solution. Potential scans $(100 \mathrm{mV} / \mathrm{s})$ of the film electrodes are shown in Figure 7A. All films display similar redox features (for values see Table 3) that can be attributed to the four-electron oxidation of water at positive potential and the two-electron reduction of water at negative potential. Both processes are accompanied by visible gas evolution $\left(\mathrm{O}_{2}\right.$ or $\left.\mathrm{H}_{2}\right)$ at the working electrode. A small reductive feature at $+0.07 \mathrm{~V}$ belongs to the reduction of electrochemically generated $\mathrm{O}_{2}$. For $\mathrm{H}_{2}$, there is no analogous oxidative feature, that is, $\mathrm{H}_{2} \mathrm{O}$ reduction is entirely irreversible under these conditions.

For $\mathrm{TBA}\left[\mathrm{Ca}_{2} \mathrm{Nb}_{3} \mathrm{O}_{10}\right]$, water oxidation and reduction are observed at +1.24 and $-1.62 \mathrm{~V}$ (NHE), respectively. These potentials are significantly larger than the calculated values
$\left(E_{\mathrm{OH}^{-}} / \mathrm{O} 2=+0.40 \mathrm{~V}\right.$ and $E_{\mathrm{H} 2 / \mathrm{H} 2 \mathrm{O}}=-0.83 \mathrm{~V}$ at $\left.\mathrm{pH}=14\right)$ with overpotentials of $\sim 0.8 \mathrm{~V}$ for both processes. All Ptcontaining catalysts reduce water more easily with measured values ranging from -1.36 to $-1.42 \mathrm{~V}$. Interestingly, water oxidation in the Pt-containing samples also occurs at slightly more favorable potentials, but the effect is less pronounced than for water reduction. Comparing the values for water reduction (Table 3$), \operatorname{Pt}($ cit) nanoparticles $(-1.38$ to $-1.42 \mathrm{~V}$ ) are slightly less active than grown $\mathrm{Pt}$ nanoparticles $(-1.36 \mathrm{~V})$, which indicates a possible retarding effect of the citrate groups on the metal surface. Among the samples with grown Pt particles, the catalyst without the amine linker requires a less negative potential for water reduction. Among catalysts with $\mathrm{Pt}(\mathrm{cit})$, the one with the shorter APS linker is somewhat better $(-1.38 \mathrm{~V})$ than the one with the AEAUS linker $(-1.42 \mathrm{~V})$. This suggests that charge transport across the $\mathrm{Pt} / \mathrm{Ca}_{2} \mathrm{Nb}_{3} \mathrm{O}_{10}$ interface is an activity-determining factor in these catalysts.

Figure 7B compares the cyclic voltammogram of the $\mathrm{IrO}_{2-}$ containing catalyst with that for $\mathrm{TBA}\left[\mathrm{Ca}_{2} \mathrm{Nb}_{3} \mathrm{O}_{10}\right]$. It can be seen that the water oxidation is shifted by $0.6 \mathrm{~V}$ to a more favorable potential of $+0.61 \mathrm{~V}$, which is quite close to the thermodynamic value at $\mathrm{pH}=14$. However, if the potential is cycled repeatedly down to $-1.47 \mathrm{~V}$, the oxidative current 
observed at $+0.61 \mathrm{~V}$ diminishes quickly, that is, the catalytic effect degrades. This indicates that at $-1.47 \mathrm{~V}$ the $\mathrm{IrO}_{2}$ nanoparticles are reduced to elemental Ir, in agreement with the XPS results for the irradiated material (see above).

On the basis of the electrochemical data, $\mathrm{IrO}_{2}$ (cit)-APS- $\left[\mathrm{Ca}_{2}-\right.$ $\mathrm{Nb}_{3} \mathrm{O}_{10}$ ] is a very effective electrochemical water oxidation catalyst. This suggests that the lack of oxygen evolution during irradiation is not due to inefficiency of water oxidation, but due to inefficient hole transfer from APS- $\left[\mathrm{Ca}_{2} \mathrm{Nb}_{3} \mathrm{O}_{10}\right]$ to $\mathrm{IrO}_{2}$ and adsorption of $\mathrm{O}_{2}$ to the catalyst surface, as discussed above. Because of the lack of an efficient $\mathrm{H}_{2}$ reduction site (e.g., $\mathrm{Pt}$ ), electrons accumulate on the nanosheets, building up a reducing potential that eventually becomes sufficient to reduce $\mathrm{IrO}_{2}$ to $\operatorname{Ir}(0)$. This problem might be solved by incorporating $\mathrm{Pt}$ nanoparticles into $\mathrm{IrO}_{2}$ (cit)-APS- $\left[\mathrm{Ca}_{2} \mathrm{Nb}_{3} \mathrm{O}_{10}\right]$ or by replacing $\mathrm{IrO}_{2}$ with a different hole-acceptor. Work toward the fabrication of optimized three-component nanostructures is underway.

\section{Conclusion}

In conclusion, we have presented a modular assembly approach for the generation of two-component nanostructures for photocatalytic hydrogen evolution from water. The catalysts are formed by either photochemical growth $(\mathrm{Pt})$ onto the semiconductor nanosheets or assembly of the preformed components ( $\mathrm{TBA}\left[\mathrm{Ca}_{2} \mathrm{Nb}_{3} \mathrm{O}_{10}\right], \mathrm{Pt}(\mathrm{cit}), \mathrm{IrO}_{2}$ (cit)). The structures can be supported by direct chemical bonds between the nanomaterials or held together by $\gamma$-aminoalkylsilyl linkers. Under UV irradiation, all structures are catalytically active for photochemical $\mathrm{H}_{2}$ evolution from water with decreasing activity in the series Pt- $\left[\mathrm{HCa}_{2} \mathrm{Nb}_{3} \mathrm{O}_{10}\right]>\mathrm{Pt}$ (cit)-APS- $\left[\mathrm{Ca}_{2} \mathrm{Nb}_{3} \mathrm{O}_{10}\right]>\mathrm{Pt}$ (cit)-AEAUS$\left[\mathrm{Ca}_{2} \mathrm{Nb}_{3} \mathrm{O}_{10}\right]>\mathrm{IrO}_{2}$ (cit)-APS- $\left[\mathrm{Ca}_{2} \mathrm{Nb}_{3} \mathrm{O}_{10}\right]>\mathrm{TBA}\left[\mathrm{Ca}_{2} \mathrm{Nb}_{3} \mathrm{O}_{10}\right]$. The trend can be rationalized by assuming that citrate molecules reduce the catalytically active area on $\mathrm{Pt}$ and organic linkers impede electron transport from the nanosheets to the $\mathrm{Pt}$ cocatalyst. The same trend is observed when the electrochemical potentials for water reduction are compared. In the absence of $\mathrm{Pt}$, little $\mathrm{H}_{2}$ is evolved because of the lack of water reduction sites on the catalysts. Hydrogen but not $\mathrm{O}_{2}$ evolution from water is achieved with $\mathrm{IrO}_{2}$ (cit)-APS- $\left[\mathrm{Ca}_{2} \mathrm{Nb}_{3} \mathrm{O}_{10}\right]$, which undergoes photoreduction to Ir-APS- $\left[\mathrm{Ca}_{2} \mathrm{Nb}_{3} \mathrm{O}_{10}\right]$. Ongoing work in this laboratory is devoted to elucidating the excited-state dynamics in these systems and to extending the synthetic concept to optimized three component nanostructures with separate sites for water oxidation and reduction.

Acknowledgment. This work was supported by an Energy Innovation Startup Grant of the California Energy Commission.

Supporting Information Available: Additional XPS data. This material is available free of charge via the Internet at http:// pubs.acs.org.

\section{References and Notes}

(1) Lewis, N. S.; Nocera, D. G. Proc. Natl. Acad. Sci. U.S.A. 2006, 103, 15729.

(2) Fujishima, A.; Honda, K. Bull. Chem. Soc. Jpn. 1971, 44, 1148.

(3) Fujishima, A.; Honda, K. Nature 1972, 238, 37.

(4) Kamat, P. V. J. Phys. Chem. C 2007, 111, 2834.

(5) Osterloh, F. E. Chem. Mater. 2008, 20, 35.

(6) Maeda, K.; Domen, K. J. Phys. Chem. C 2007, 111, 7851.
(7) Kudo, A. Int. J. Hydrogen Energy 2006, 31, 197.

(8) Zou, Z. G.; Ye, J. H.; Sayama, K.; Arakawa, H. Nature 2001, 414, 625.

(9) Bard, A. J.; Fox, M. A. Acc. Chem. Res. 1995, 28, 141.

(10) Domen, K.; Kudo, A.; Tanaka, A.; Onishi, T. Catal. Today 1990 8,77 .

(11) Tabata, S.; Ohnishi, H.; Yagasaki, E.; Ippommatsu, M.; Domen, K. Catal. Lett. 1994, 28, 417.

(12) Kudo, A.; Kato, H.; Nakagawa, S. J. Phys. Chem. B 2000, 104, 571.

(13) Ebina, Y.; Sasaki, T.; Harada, M.; Watanabe, M. Chem. Mater. 2002, 14, 4390.

(14) Ebina, Y.; Sakai, N.; Sasaki, T. J. Phys. Chem. B 2005, 109, 17212.

(15) Compton, O. C.; Carroll, E. C.; Kim, J. Y.; Larsen, D. S.; Osterloh,

F. E. J. Phys. Chem. C 2007, 111, 14589.

(16) Carroll, E. C.; Compton, O. C.; Madsen, D.; Osterloh, F. E.; Larsen, D. S. J. Phys. Chem. C 2008, 112, 2394.

(17) Kim, J. Y.; Osterloh, F. E.; Hiramatsu, H.; Dumas, R. K.; Liu, K. J. Phys. Chem. B 2005, 109, 11151.

(18) Kim, J. Y.; Hiramatsu, H.; Osterloh, F. E. J. Am. Chem. Soc. 2005, $127,15556$.

(19) Kim, J. Y.; Osterloh, F. E. J. Am. Chem. Soc. 2006, 128, 3868.

(20) Harriman, A.; Pickering, I. J.; Thomas, J. M.; Christensen, P. A. J. Chem. Soc., Faraday Trans. I 1988, 84, 2795.

(21) Hoertz, P. G.; Kim, Y.; Youngblood, W. J.; Mallouk, T. E. J. Phys. Chem. B 2007, 111, 6485.

(22) Jacobsen, A. J.; Johnson, J. W.; Lewandowski, J. T. Inorg. Chem. 1985, 24, 3727.

(23) Dion, M.; Ganne, M.; Tournoux, M. Mater. Res. Bull. 1981, 16, 1429 .

(24) Fang, M.; Kim, C. H.; Saupe, G. B.; Kim, H. N.; Waraksa, C. C.; Miwa, T.; Fujishima, A.; Mallouk, T. E. Chem. Mater. 1999, 11, 1526.

(25) Schaak, R. E.; Mallouk, T. E. Chem. Mater. 2000, 12, 2513.

(26) Harriman, A.; Millward, G. R.; Neta, P.; Richoux, M. C.; Thomas, J. M. J. Phys. Chem. 1988, 92, 1286.

(27) Brugger, P.; Cuendet, P.; Gratzel, M. J. Am. Chem. Soc. 1981, 103, 2923.

(28) Harriman, A.; Thomas, J. M.; Millward, G. R. New J. Chem. 1987, $11,757$.

(29) Hara, M.; Waraksa, C. C.; Lean, J. T.; Lewis, B. A.; Mallouk, T. E. J. Phys. Chem. A 2000, 104, 5275 .

(30) Kuhn, H. J.; Braslavsky, S. E.; Schmidt, R. Pure App. Chem. 2004, $76,2105$.

(31) Nahor, C. S.; Hapiot, P.; Neta, P.; Harriman, A. J. Phys. Chem. 1991, 95, 616.

(32) Silverstein, R. M.; Webster, F. X. Spectrometric Identification of Organic Compounds, 6th ed.; Wiley: New York, 1998.

(33) Shimizu, K.; Tsuji, Y.; Hatamachi, T.; Toda, K.; Kodama, T.; Sato, M.; Kitayama, Y. Phys. Chem. Chem. Phys. 2004, 6, 1064.

(34) Shimizu, K.; Itoh, S.; Hatamachi, T.; Kodama, T.; Sato, M.; Toda, K. Chem. Mater. 2005, 17, 5161 .

(35) Brito, R.; Tremont, R.; Cabrera, C. R. J. Electroanal. Chem. 2004, $574,15$.

(36) Rozkiewicz, D. I.; Kraan, Y; Werten, M. W. T; Wolf, F. A. d; Subramaniam, V.; Ravoo, B. J.; Reinhoudt, D. N. Chem.-Eur. J. 2006, 12, 6290 .

(37) Diegoli, S.; Mendes, P. M.; Baguley, E. R.; Leigh, S. J.; Iqbal, P.; Garcia Diaz, Y. R.; Begum, S.; Critchley, K.; Hammond, G. D.; Evans, S. D.; Attwood, D.; Jones, I. P.; Preece, J. A. J. Exp. Nanosci. 2006, 1, 333

(38) Galinska, A.; Walendziewski, J. Energy Fuels 2005, 19, 1143.

(39) Liu, H.; Yuan, J.; Shangguan, W. Energy Fuels 2006, 20, 2289.

(40) Buhler, N.; Meier, K.; Reber, J. F. J. Phys. Chem. 1984, 88, 3261.

(41) Bos, M. E. Tetra- $n$-butylammonium Hydroxide. In $e$-EROS Encyclopedia of Reagents for Organic Synthesis; John Wiley \& Sons, Ltd.: New York, 2006.

(42) Sayama, K.; Yase, K.; Arakawa, H.; Asakura, K.; Tanaka, A.; Domen, K.; Onishi, T. J. Photochem. Photobiol. A 1998, 114, 125.

(43) Sayama, K.; Arakawa, H. J. Chem. Soc., Chem. Commun. 1992 150 .

(44) Choi, J.; Lim, J. H.; Lee, J.; Kim, K. J. Nanotechnology 2007, 18, 055603 .

(45) Hara, M.; Asami, K.; Hashimoto, K.; Masumoto, T. Electrochim. Acta. 1983, 28, 1073.

(46) Harriman, A.; Nahor, G. S.; Mosseri, S.; Neta, P. J. Chem. Soc., Faraday Trans. I 1988, 84, 2821. 